\title{
Pentingnya Stimulasi Dini untuk Merangsang Perkembangan Bayi dan Balita Terutama pada Bayi Risiko Tinggi
}

\author{
Soedjatmiko
}

\begin{abstract}
Bayi risiko tinggi ialah bayi yang secara klinis belum menunjukkan hambatan perkembangan tetapi berpotensi untuk mengalami gangguan perkembangan akibat faktor risiko biomedik, lingkungan psikososial atau sosial ekonomi. Faktor risiko tersebut secara langsung atau tidak langsung dapat mengganggu perkembangan otak, sehingga mengganggu perkembangan gerak, komunikasi, kognitif, emosi-sosial dan perilaku. Plastisitas otak adalah kemampuan susunan saraf untuk menyesuaikan diri berupa perubahan anatomi, kemampuan neurokimiawi atau perubahan metabolik. Stimulasi dini adalah rangsangan auditori, visual, taktil dan kinestetik yang diberikan sejak perkembangan otak dini, dengan harapan dapat merangsang kuantitas dan kualitas sinaps sel-sel otak, untuk mengoptimalkan fungsi otak. Stimulasi dini harus memperhatikan tahapan maturasi otak, waktu, jenis stimulasi, cara melakukan stimulasi, intensitas, perbedaan individual, keterpaduan dan dukungan program lain yang berkelanjutan. Peran dokter dan perawat di ruang bayi baru lahir, serta orangtua sangat penting, oleh karena itu mereka perlu dibekali pengetahuan dan ketrampilan mengenai stimulasi dini.
\end{abstract}

Kata kunci: bayi risiko tinggi, stimulasi dini, perkembangan otak

B ayi risiko tinggi ialah bayi yang secara klinis belum menunjukkan hambatan perkem-bangan tetapi berpotensi untuk mengalami gangguan perkembangan ${ }^{1}$ akibat faktor risiko biomedik maupun lingkungan psikososial, atau sosial ekonomi ${ }^{2,3}$ yang dialami sejak masa konsepsi sampai masa neonatal. ${ }^{2,4}$

\footnotetext{
Alamat korespondensi:

Dr. Soedjatmiko, Sp.A(K), MSi.

Divisi Tumbuh Kembang Pediatri Sosial. Departemen Ilmu Kesehatan Anak FKUI-RSCM. Jl. Salemba no. 6, Jakarta 10430.

Telepon: 021-3160622. Fax.021-3913982
}

Risiko biomedik yang berpotensi untuk menghambat tumbuh kembang antara lain: prematuritas, perdarahan intrakranial, hambatan pertumbuhan intra uterin, ensefalopati iskemik hipoksik, hipoglikemia, polisitemia, hiperbilirubinemia, kelainan kongenital, infeksi, kejang neonatal, ibu pengguna NAPZA dll Faktor risiko biomedik yang tersering adalah prematuritas. ${ }^{2}$ Risiko lingkungan psikososial atau sosial ekonomi yang dapat menghambat tumbuh kembang antara lain status sosial ekonomi yang buruk (kemiskinan, pendidikan orangtua rendah, perumahan yang buruk, jumlah anak terlalu banyak), ibu terlalu muda, ibu dengan mental retardasi, gangguan kejiwaan, pengguna narkoba, riwayat perlakuan salah di dalam keluarga atau perceraian. ${ }^{2}$ 
Sari Pediatri, Vol. 8, No. 3, Desember 2006

\section{Dampak Faktor Risiko pada Perkembangan Bayi}

Faktor risiko tersebut di atas secara langsung atau tidak langsung dapat mengganggu perkembangan gerak, komunikasi, kognitif, emosi-sosial dan perilaku. Semakin banyak faktor risiko, semakin banyak dan berat aspek perkembangan yang terganggu. Bentuk gangguan perkembangan yang tersering adalah palsi serebral, retardasi psikomotor, gangguan penglihatan, pendengaran, bicara dan perilaku ${ }^{2,4}$ Umumnya gangguan perkembangan tersebut bersumber pada gangguan perkembangan otak akibat pengaruh faktor risiko tersebut di atas secara langsung atau tidak langsung. ${ }^{2}$

\section{Tahapan perkembangan beberapa struktur otak}

Perkembangan otak berlangsung secara bertahap. Selsel saraf bayi berproliferasi sejak sebelum lahir kemudian mengalami perkembangan berupa migrasi (sampai umur sekitar 6 bulan), differensiasi (menjadi berbagai macam sel neuron yang bercabang-cabang), sinaptogenesis (membentuk hubungan antar sel sejak trimester III sampai umur 4 tahun) dan mielinansi (sampai umur $4-5$ tahun) $)^{5}$ Pematangan fungsi otak tidak semata-mata oleh proses biologis, tetapi sangat dipengaruhi pula oleh kualitas pengalaman interaksi dengan lingkungan pengasuhan. ${ }^{6}$

\section{Tahapan maturasi fungsi otak}

Dengan menggunakan Positron Emission Tomography (PET) dan metoda autoradiografi dapat diukur penggunaan glukosa di korteks otak yang berkaitan dengan peningkatan sinaptogenesis, pematangan fungsi sel syaraf dan maturasi perilaku. ${ }^{7}$

\section{Bayi baru lahir}

Pada bayi baru lahir kecepatan metabolisme penggunaan glukosa secara regional atau lokal $30 \%$ lebih rendah dari pada dewasa muda, metabolisme tertinggi di korteks sensori dan motor, talamus, batang otak dan vermis serebelum. Sebagian besar korteks serebri pada masa neonatal kurang aktif sehingga perilaku, refleks batang otak dan integrasi visuomotor bayi baru lahir masih terbatas. Aktivitas metabolik di amigdala dan korteks singuli cukup tinggi, menandakan struktur sistem limbik sudah aktif, sehingga bayi baru lahir mampu melakukan interaksi emosi dengan ibunya yang sangat penting dalam pembentukan ikatan hubungan ibu dan bayi (mother infant bonding / attachment). ${ }^{7}$

\section{Umur 0 - 4 tahun}

Pada umur $2-3$ bulan terlihat peningkatan penggunaan glukosa di korteks parietal, temporal dan korteks visual primer, basal gangila serta hemisfer serebelum. Perubahan ini bersamaan dengan peningkatan kemampuan integrasi visuospasial dan visuosensorimotor. ${ }^{7}$ Pada umur $6-8$ bulan korteks frontal bagian lateral dan inferior secara fungsional lebih aktif, dan pada umur 8 - 12 bulan bagian dorsal dan medial korteks frontal menunjukkan peningkatan penggunaan glukosa. Perubahan metabolisme pada korteks frontal muncul bersamaan dengan munculnya perilaku kognitif bayi, misalnya mengenali orang asing, peningkatan kemampuan membedakan gambar. Peningkatan ini juga bersamaan dengan perluasan daerah dendrit dan peningkatan percabangan kapiler di korteks frontal. ${ }^{7}$ Pada umur 3 4 tahun peningkatan metabolisme mencapai 2 kali tingkat dewasa di korteks serebri. Di basal ganglia dan talamus peningkatan tidak setinggi korteks serebri, sedangkan di batang otak tidak terlihat perubahan. ${ }^{7}$

\section{Umur 4 - 10 tahun}

Tingkat metabolisme glukosa di korteks tidak meningkat lagi, tetapi tetap tinggi ( 2 kali dewasa). Hal ini sesuai dengan penelitian aliran darah serebral anak umur 3-11 tahun sekitar 1,8 kali dewasa muda, sedangkan penggunaan oksigen otak sekitar 1,3 kali dewasa muda. ${ }^{7}$

\section{Umur 10 - 18 tahun}

Mulai umur 9 tahun tingkat metabolisme glukosa korteks serebri menurun dan mencapai tingkat metabolisme dewasa pada umur $16-18$ tahun. Semua daerah di korteks serebri menunjukkan tahapan perkembangan yang hampir sama, yang berbeda hanya di basal ganglia dan talamus, sedangkan di batang otak tidak menunjukkan perubahan yang bermakna. ${ }^{7}$ 


\section{Prinsip Umum Stimulasi Psikososial Bayi Risiko Tinggi}

\section{Waktu}

Intervensi yang dilakukan sejak dini dan berlangsung lebih lama akan memberikan manfaat lebih besar dibanding dengan intervensi yang terlambat atau dalam waktu yang lebih singkat. Intervensi yang dilakukan sejak masa neonatal menunjukkan manfaat terbesar pada kemampuan kognitif dan pra akademik. Intervensi yang dilakukan setiap hari dan dimonitor setiap bulan selama 3 tahun menunjukkan hasil yang nyata untuk perkembangan intelektual dan perilaku pada umur 36 bulan. ${ }^{8}$ Pengaruh intervensi lebih bermakna pada umur 48 bulan. Dibandingkan tanpa intervensi, pada kelompok intervensi memperlihatkan peningkatan kemampuan kognitif sedangkan kelompok kontrol menunjukan perburukan. ${ }^{9}$ Pada umur 8 tahun anak yang telah mendapatkan intervensi berkelanjutan sejak bayi (selama 8 tahun) menunjukkan kemampuan terbaik dibanding kelompok lain dalam hal membaca dan matematika, melebihi kemampuan anak yang mendapat latihan sejak TK (selama 5 tahun) atau kelompok yang dilatih hanya di sekolah dasar saja. ${ }^{9}$

\section{Jenis Stimulasi}

Tidak semua jenis stimulasi mempunyai effektifitas yang sama, bahkan bayi-bayi yang mendapat stimulasi yang sama menunjukkan hasil yang berbeda. Berbagai parameter stimulasi perlu dipertimbangkan, termasuk jumlah, tipe, saat, pola, kualitas stimulasi, disamping berbagai faktor risiko yang ada pada bayi. ${ }^{9}$

Umumnya untuk bayi dianjurkan pendekatan rangsangan multimodal yang meliputi rangsang ${ }^{1}$ taktil (pijat, fleksi ekstensi, posisi), vestibular kinestetik ( menggoyang, mengayun), pendengaran (menyanyi, musik, rekaman susra ibu, irama jantung ibu), dan visual (gerakan, warna, bentuk)

Tetapi konon stimulasi multimodal lebih banyak menimbulkan stres pada bayi daripada stimulasi cara tunggal. ${ }^{10}$ Sebelum umur 3 tahun stimulasi diarahkan untuk mencapai semua aspek perkembangan (penglihatan, pendengaran, kognitif, sosial-kemandirian, gerak halus, kasar). Sesudah umur 3 tahun stimulasi diarahkan lebih spesifik untuk kesiapan akademik: menggambar, mengenal bentuk, huruf, angka, menulis, membaca, berhitung, disamping emosi-sosial dan kemandirian. ${ }^{11}$

\section{Intensitas}

Program yang lebih intensif akan memberikan hasil yang lebih besar. Anak dan orangtua yang lebih aktif dan teratur mengikuti program menunjukkan kemajuan yang lebih besar. ${ }^{8}$ Secara individual isyarat perilaku bayi dapat digunakan sebagai penentu intensitas yang cocok untuk bayi Tanda ketegangan atau perilaku yang menghindar menunjukan stimulasi harus dihentikan. ${ }^{10}$ Stimulasi yang berlebihan akan memperburuk ketidakstabilan sistem saraf otonom yang dapat menimbulkan hipoksia, apne dan bradikardi pada bayi prematur. ${ }^{12}$ Intervensi yang dilakukan setiap hari dan dimonitor setiap bulan selama 3 tahun menunjukkan hasil yang nyata untuk perkembangan intelektual dan perilaku pada umur 36 bulan. Bayi berat lahir rendah yang berperan aktif dalam intervensi kemungkinan untuk menjadi retardasi mental lebih kecil 9 kali dibandingkan dengan yang tidak aktif melakukan intervensi. ${ }^{9}$ Infant Health and Developmental Program melaporkan bahwa tingkat perkembangan intelektual berkaitan erat dengan tingkat partisipasi, tetapi tidak berkaitan dengan berat lahir atau pendidikan orangtua. ${ }^{9}$ Bayi yang diketahui sejak dini mempunyai kecacatan, tindakan intervensi $1-31 / 2$ hari perminggu tidak menunjukkan manfaat. Intervensi yang sama pada anak dengan risiko tinggi sosial ekonomi juga tidak menunjukkan hasil yang bermakna Jadi intensitas harus lebih banyak untuk mendapatkan efek positif yang terukur. ${ }^{9}$

\section{Perbedaan Individual}

Hasil stimulasi pada beberapa individu dengan metoda yang sama dapat menghasilkan kemajuan yang berbeda, tergantung pada faktor risiko sebelum intervensi dan derajat kecocokan antara program dengan cara belajar anak. Bayi dengan risiko biologis lebih besar akan mendapatkan kemajuan yang lebih sedikit walaupun kemajuannya bermakna. Anak dengan kemampuan yang relatif lebih tinggi mendapatkan manfaat lebih banyak melalui instruksi langsung, sedangkan anak yang kemampuannya relatif lebih rendah mendapatkan kemajuan melalui instruksi tidak langsung. ${ }^{9}$ 
Sari Pediatri, Vol. 8, No. 3, Desember 2006

\section{Keterpaduan}

Stimulasi lebih baik jika diberikan oleh orangtua dengan memanfaatkan anggota keluarga, faktor-faktor lingkungan sosio- ekonomi, dan melibatkan tim interdisiplin termasuk dokter, perawat, psikologi, terapi okupasi dan fisik, dan pekerja sosial. ${ }^{10,13,14}$ Keterpaduan yang menggabungkan cara langsung dan tidak langsung mempunyai pengaruh yang kuat, terutama bila tersedia sarana untuk hidup sehat dan layanan sosial untuk keluarga (transportasi, bantuan kebutuhan yang mendesak dan dukungan untuk orangtua). Stimulasi di rumah selama 1 tahun pada bayi berat lahir rendah dan keluarganya menunjukkan bahwa intervensi yang berfokus pada orang tua menunjukkan hasil yang besar.

Penelitian Resnick $\mathrm{dkk}^{15}$ melaporkan hasil yang sama setelah intervensi perkembangan yang dimulai sejak mereka di rumah sakit, kemudian dilanjutkan di rumah sampai umur 2 tahun. Intervensi terutama difokuskan pada orangtua untuk memperkuat kualitas interaksi orangtua dan bayi. Kelompok eksperimental menunjukkan angka lebih tinggi ketimbang kontrol dengan skala Bayley Mental dan Motor pada umur 12 dan 24 bulan. Kunjungan rumah seminggu 3 kali akan menghasilkan kemajuan yang bermakna. Orangtua dan anggota keluarga lain di rumah merupakan faktor yang penting untuk memberikan pembelajaran sejak dini. ${ }^{16}$ Pendapat lain menyimpulkan bahwa intervensi langsung pada bayi untuk meningkatkan pengalaman pembelajaran sehari-hari menunjukkan hasil yang lebih banyak dan lebih lama dibandingkan cara tidak langsung. Cara langsung lebih banyak meningkatkan kemampuan intelegensia anak terutama yang mempunyai faktor-faktor risiko yang serius: ekonomi, bilologis, atau kedua faktor tersebut. ${ }^{8}$

\section{Perlu dukungan yang berkelanjutan}

Pengaruh positif akan berkurang jika tidak ada dukungan yang adekuat untuk mempertahankan sikap dan perilaku tersebut. Dampak jangka panjang stimulasi dini pada nilai IQ semakin lama akan berkurang. Beberapa faktor yang terkait antara lain anak dengan riwayat risiko tinggi tidak mampu mempertahankan manfaat efektivitas intervensi dini, karena harus melanjutkan perkembangan dalam kecepatan yang umum di sekolah. Lingkungan sekolah yang buruk, kesehatan yang suboptimal, lingkungan rumah yang kacau dan berbagai faktor lain mempengaruhi perkembangan anak pada usia selanjutnya. ${ }^{8}$ Bagi anak yang telah mendapatkan intervensi berkelanjutan selama 8 tahun menunjukkan kemampuan terbaik dibanding kelompok lain dalam hal membaca dan matematik, melebihi kemampuan anak yang mendapat latihan selama 5 tahun dan kelompok yang dilatih hanya di sekolah dasar saja. ${ }^{8}$ Pada kelompok intervensi yang dimulai sejak TK sampai umur 8 tahun tidak menunjukan peningkatan IQ.

\section{Stimulasi di Ruang Rawat Bayi}

\section{Perasaan dan sikap orangtua bayi risiko tinggi}

Orangtua umumnya tidak siap menghadapi kenyataan bahwa bayinya berbeda dari yang lain karena adanya faktor risiko. ${ }^{17}$ Bayi risiko tinggi kadang-kadang dirawat di ruang khusus, dalam inkubator tertutup, dengan kabel dan selang, sehingga orangtua sulit untuk melihat, menyentuh, tidak dapat mengambil, menggendong atau menimang bayinya. Perasaan dan sikap orangtua juga dipengaruhi oleh penampilan fisik bayi dan sikap/perilaku dokter atau perawat yang segera melakukan intervensi pada bayinya dengan serius. $^{18}$

Kepedulian ibu terfokus kepada keselamatan si bayi semata. Ketidaktentuan tentang keselamatan dan kemampuan dimasa depan menyebabkan kecemasan, kecewa, sedih, marah dan merasa bersalah, selain merasa adanya beban karena bayinya membutuhkan lebih banyak perawatan, padahal keselamatannya belum dapat dipastikan. ${ }^{17}$ Perasaan dan sikap tersebut menghambat tumbuhnya ikatan kasih sayang ibu dan bayi yang merupakan landasan interaksi ibu dan bayi, sangat penting untuk merangsang perkembangannya. ${ }^{18}$

Bila orangtua tidak terlibat, bayi akan merasa ikatan emosialnya kurang kuat, dan merasa tidak aman. ${ }^{17}$ Bayi ini cenderung tak menentu (ambivalen), menghindar, tidak beraturan dalam usaha membentuk hubungan dengan orang lain. Sedang pada bayi yang selalu merasa aman mempunyai perkembangan emosi sosial yang lebih baik. ${ }^{17,18}$

Ketidaktahuan orangtua tentang keadaan bayinya dapat menimbulkan kecemasan yang berlebihan, oleh karena itu orang tua harus segera diberi penjelasan tentang prognosis, kemungkinan perjalan penyakitnya, 
kemungkinan penyulit, gejala sisa, agar mereka dapat mengetahui keadaan bayinya secara proporsional, dan tidak menimbulkan kecemasan yang berlebihan, bahkan diharapkan dapat menerima kenyataan tersebut secara bertahap. ${ }^{17,} 18$

\section{Pentingnya pelatihan untuk orangtua bayi risiko tinggi}

Orangtua secara bertahap dilatih mengasuh bayinya sejak di NICU, di ruang rawat bayi atau rawat gabung dengan tujuan, ${ }^{19}$

1. Ibu dapat mengerti keadaan khusus bayinya dan potensi perkembangannya sehingga menghilangkan ketakutan dan kecemasan serta mendorong ibu untuk menikmati kebersamaan dengan bayinya.

2. Meningkatkan kepekaan ibu terhadap isyarat bayinya, terutama yang mengisyaratkan kelebihan rangsang atau kelelahan, serta mengetahui kapan bayi dalam keadaan siap untuk berinteraksi.
3. Mengajarkan ibu berinteraksi yang sesuai dan saat yang tepat terhadap isyarat bayi tersebut. Ibu akan belajar kapan harus berisitirahat, menghibur, merangsang dan membiasakan dengan keinginan dan temperamen bayinya.

4. Meningkatkan ketrampilan membersihkan, memandikan, mengganti pakaian, memberi minum dan menenangkan bayi.

5. Untuk meningkatkan kepercayaan diri dan memperkuat kesenangan ibu terhadap bayinya.

Ibu dilatih berinteraksi secara bertahap (Tabel 1) sesuai keadaan bayi dan ibunya.

Bilamana keadaan bayi dan ibu sudah memungkinkan (misalnya sudah dipindahkan di ruang bayi atau rawat gabung), maka ibu dilatih memberikan perawatan sehari-hari secara bertahap (Tabel 2) ${ }^{19}$

Ibu dianjurkan sering memandang wajah dan menatap mata bayi, mengajak bayinya tersenyum, berbicara yang lembut dan dikombinasi dengan sentuhan sehingga memberikan 3 rangsangan

Tabel 1. Stimulasi psikososial untuk bayi risiko tinggi ${ }^{19}$

\begin{tabular}{ll}
\hline Kegiatan & Cara berinteraksi \\
\hline Penglihatan & Menarik perhatian bayi, dekatkan wajah ibu \\
& Pertahankan kontak mata yang lama \\
Ubah ekspresi wajah untuk mempertahankan interaksi visual, menggunakan senyuman, \\
ekspresi kaget, gerakan lidah \\
Gerakan kepala, ajak bayi anda untuk mengikuti gerakan kepala \\
Gerakan, anggukan dan gelengkan kepala untuk mempertahankan interaksi \\
Tirukan ekspresi wajah bayi \\
Gerakan benda berwarna terang untuk membantu pemfokusan bayi dan mengikutinya \\
Pegang bayi posisi tegak sehingga ia dapat melihat melampauai bahu orangtua \\
Atur kursi bayi sehingga ia dapat melihat ke orangtua \\
Gunakan suara anda untuk berbagai cara berkomunikasi dengan bayi (bernyanyi, bergumam, \\
berkotek, memanggil nama, bercakap) \\
Berusaha agar bayi menggerakkan matanya dan kepalanya kearah suara anda \\
Tiru suara bayi \\
Gunakan benda untuk menimbulkan suara (bel, musik) \\
Membungkus, menggendong, mengatur posisi \\
Sentuhan, tepukan, pijat bayi dengan cara menenangkan dan berirama \\
Manfaatkan refleks bayi untuk interaksi (refleks isap, refleks memegang) \\
Pegang dan timang bayi \\
Ayunkan bayi ketika diam, dan hibur dengan menggoyang ketika rewel \\
Bergerak berkeliling dengan bayi tegak di bahu \\
Kombinasi gerakan badan dan wajah dengan mencium dan menyundul bayi \\
Bermain sambil mengganti baju atau memandikan
\end{tabular}


Sari Pediatri, Vol. 8, No. 3, Desember 2006

Tabel 2. Cara melakukan perawatan/pengasuhan bayi risiko tinggi ${ }^{19}$

\begin{tabular}{ll}
\hline Kegiatan & Cara melakukan perawatan/pengasuhan \\
\hline Membangunkan & Masuk ke kamar perlahan, nyalakan lampu, buka korden perlahan \\
& Bersuara lembut \\
& Buka selimut bertahap \\
& Hindari stimulasi yang berlebihan, walaupun bayi sukar dibangunkan \\
Mengganti pakaian & Sesuaikan suhu ruangan \\
& Hindari perubahan posisi yang mendadak \\
& Tahan dan ikutkan tungkai dan lengan ketika merubah posisi \\
& Lakukan rangsang sentuhan yang ringan \\
& Sering menghibur mungkin perlu, tetapi beri kesempatan bayi untuk menenangkan \\
& diri sendiri \\
& Perhatikan kebutuhan minum individual \\
& Saat pemberian minum bersamaan dengan saat bangun spontan \\
& Hindari suara yang keras \\
& Cegah gerakan bayi yang berlebihan dengan membungkus atau memeluk bayi \\
& rapat ke tubuh \\
& Perlahan, perhatikan tanda kelelahan, ketidakstabilan (tremor, pucat, terkejut) \\
& Menahan permukaan badan bagian depan mungkin dibutuhkan, \\
& Sediakan dot atau mainan yang bisa dipegang, digigit, diisap \\
Memandikan & Beri kesempatan sering berhenti (istirahat) \\
\hline
\end{tabular}

sekaligus. Karena bayi telah akrab dengan suara orangtuanya sejak kehamilan maka suara-suara ibu akan menenangkan bayi Ketika orangtua tidak ada disitu, dapat ditinggalkan rekaman suara mereka yang menyanyikan lagu menidurkan bayi, membacakan sajak, cerita, atau seolah mengajak bermain. ${ }^{17,18}$ Orangtua sebaiknya menyentuh bayinya segera mungkin dimulai pada tungkai atau lengan yang tidak terlalu sensitif dibanding badan, misalnya dengan mengelus atau memijat lembut, bahkan dapat dilakukan hanya melalui jendela kecil di incubator. ${ }^{17,18}$ Bayi prematur yang dipijat 20 menit sehari mengalami pertambahan berat badan lebih baik, lebih sedikit henti napas, dan uji perkembangan beberapa tahun kemudian mempunyai nilai yang lebih baik dibanding bayi prematur yang tidak mendapat perhatian ini. ${ }^{17}$

Orangtua harus belajar untuk mengenal sinyal fisiologis. yang menunjukan ketidak nyamaan, atau kelelahan antara lain: sianosis, warna kulit yang bertitik-titik (mottling), nafas yang tidak teratur, henti nafas, cekukan, muntah, kejutan (starles), menyeringai (grimace), kejang (twitching), sikap tubuh, ketegangan otot, gerakan yang kaku (jerky), perubahan ketegangan otot yang tiba-tiba (abrupt) dan yang gradual. Hal tersebut menunjukan terganggunya homesostasis akibat pengaruh lingkungan: kedinginan, suara yang keras, cahaya yang menyilaukan atau gerakan yang tiba-tiba, sehingga tidak memberikan stimulasi berlebihan pada bayi prematur. ${ }^{19}$

Dalam program ini ibu belajar untuk mengenali toleransi bayi terhadap stimulasi sosial, yaitu, merangsang bayi ketika memungkinkan, dan menghentikan rangsangan bila bayi menjadi kelelahan dan manyesuaikan dengan perilaku bayi ${ }^{17}$ Juga disarankan untuk memotret bayinya sehingga setiap saat bisa dipandang untuk memperkuat ikatan emosi dan kasih sayang orangtua dan anak. Jika ibu tidak bisa hadir, maka ayah harus mengunjungi seorang diri sebagai pengganti ibu. Sebagian ayah merasa dekat dengan bayinya dan bisa memulai proses ikatan kasih sayang ayah dan bayi. Ibu yang mendapat dukungan dari suaminya dan orangtuanya lebih mampu berhadapan dengan masalah emosional dalam mengasuh bayinya. ${ }^{17,18}$ Perilaku ibu yang menunjukkan rasa kasih sayang dan kepekaan (responsiveness) terhadap bayinya mempunyai hubungan bermakna dengan perkembangan kognitif dan motivasi bayi pada umur 5 bulan. ${ }^{20}$

\section{Stimulasi di Rumah}

Stimulasi di rumah pada prinsipnya melanjutkan latihan yang telah didapat selama di rumah sakit. Pada 
keadaan ini bayi dan ibu lebih baik, dan ibu setiap saat dapat berinteraksi dengan bayi, sehingga stimulasi di rumah lebih berkembang dan bervariasi dibanding di rumah sakit. ${ }^{19}$ Peralihan perawatan dari rumah sakit ke rumah tinggal walaupun menggembirakan, sering disertai ketakutan dan keragu-raguan. ${ }^{18}$ Keluarga sering tidak siap mengantisipasi masalah akibat adanya bayi itu, sehingga ibu merasa letih, tidak mampu menyelesaikan berbagai tugas rumah tangga, merasa gagal menjadi orangtua yang sempurna. Orangtua harus belajar untuk mengatur prioritas, dan harus saling membantu. ${ }^{17}$

\section{Beberapa Pedoman Umum Stimulasi}

Orangtua menyediakan stimulasi melalui 2 cara yaitu melalui pengaturan lingkungan yang merangsang kegiatan sensorimotor, atau dengan langsung berinteraksi dengan bayinya. ${ }^{21}$

\section{Stimulasi penglihatan}

Rangsang visual sebaiknya terdiri dari warna yang mencolok, kontras gelap dan terang (garis-garis, lingkaran-lingkaran sepusat, bentuk geometrik), obyek yang bergerak dan permukaan di sekitarnya. Wajah manusia adalah obyek yang paling disukai untuk menarik perhatian, bentuknya, gerakannya dan suaranya. Tatapan wajah yang sangat dekat dan bersuara memungkinkan stimulasi visual, auditori dan taktil secara bermakna. Perubahan posisi yang sering (dari telentang ke tengkurap, dari tempat tidur ke gendongan, dari kursi ke ayunan) memungkinkan bayi mendapatkan berbagai stimulasi penglihatan dan pemandangan yang berbeda. ${ }^{21}$

\section{Stimulasi pendengaran}

Untuk merangsang pendengaran: bersuara (menirukan suara bayi, berbicara, bernyanyi) adalah sangat penting. Banyaknya dan tipe bahasa yang digunakan di rumah selama periode bayi merupakan faktor penting dalam perkembangan kecerdasan anak. Pemaparan terhadap berbagai musik, membacakan dongeng untuk bayi akan membantu rangsang pendengaran, tetapi jangan terlalu ramai dan mengganggu. Bayi yang dihujani dengan berbagai suara (suara TV, radio, teriakan, kegaduhan yang konstan) kelak sulit untuk mem- bedakan dengan menggunakan pendengaran dan perhatian. ${ }^{21}$

\section{Stimulasi taktil (perabaan, sentuhan)}

Rangsang raba (taktil) adalah rangsang sensori yang paling penting untuk perkembangan yang sehat. Sensasi sentuhan adalah yang paling berkembang pada saat lahir, dan telah berfungsi sejak sebelum lahir, jauh sebelum fungsi sensasi lainnya berkembang. Memegang, menimang, mengurut, menepuk, menggoncang dan gerakan adalah sangat penting, termasuk memijat dan memandikan. Mainan yang mempunyai permukaan yang bervariasi (lembut, licin, fleksibel dan kaku) juga memungkinkan pengalaman perabaan yang beragam. ${ }^{21}$

\section{Stimulasi pengecapan dan pembauan}

Variasi rasa dan tekstur makanan memungkinkan rangsang pengecapan dan pembauan. ${ }^{21}$

\section{Koordinasi visual dan gerak}

Koordinasi mata dan tangan dapat diperkuat dengan mainan, penempatan mainan di luar jangkauan anak yang masih memungkinkan bayi menggeser tubuhnya untuk meraihnya, menyediakan obyek yang dapat dipukulkan, ditumpahkan dan dimasukkan kembali (dumped and filled). ${ }^{21}$

\section{Peran orangtua}

Jika orangtua mengembangkan lingkungan yang menarik maka bayi dapat belajar sendiri lingkungannya. Orangtua adalah guru utama anak dimulai pada masa bayi, terhadap contoh perilaku orangtua dan keterlibatan dalam bermain adalah penting untuk perkembangan anak. Lima peran orangtua adalah 5P, penyediaan lingkungan pembelajaran, sikap orangtua dapat diramalkan (predictability), bermain dengan proses ping-pong, membiarkan dan mendorong bayi secara persisten untuk tetap tertarik dan didalam aktivitas, jangan menjadi professor (selalu berbicara, tidak memberi kesempatan pada bayi). Selain itu orangtua harus merangsang $4 \mathrm{R}$ yaitu responsiveness, reasoning, rasionality dan reading. Sedangkan warm (kehangatan, mencintai, perduli) sangat diperlukan agar $5 \mathrm{P}$ dan $4 \mathrm{R}$ berfungsi baik. 
Sari Pediatri, Vol. 8, No. 3, Desember 2006

\section{Stimulasi Berdasarkan Kelompok Umur $11,17,18,21-27$}

\section{Umur $0-3$ bulan}

Berikan rasa nyaman, aman, tunjukkan perhatian dan kasih sayang dengan cara : memeluk menggendong, menyelimuti, memberikan ASI, menghibur, membersihkan badan, mengganti popok basah. Rangsanglah penglihatan, perkembangan sosial dan kognitif bayi dengan cara: menatap mata bayi dari jarak sekitar $30 \mathrm{~cm}$, mengajak tersenyum, membalas senyuman, menggantung mainan yang bisa bergerak, menggerakkan mainan berwarnawarni ke kanan-kiri, ke depan-belakang. Rangsanglah pendengaran, perkembangan berbahasa, sosial dan kognitif bayi dengan: mengajak berbicara, menirukan ocehan bayi, menggerakan mainan yang berbunyi, memperdengarkan musik dll. Rangsanglah perkembangan gerak kasar dan keseimbangan dengan melatih bayi mengangkat kepala, dada, miring, tengkurap. Rangsanglah perkembangan gerak halus, perabaan dan perkembangan kognitif dengan memberikan mainan yang dapat diraih, diraba, dipegang, digenggam, diremas.

\section{Umur $3-6$ bulan}

Lanjutkan perangsangan dengan yang lebih kompleks, seperti: bermain cilukba, bayi melihat bayangan dirinya di cermin, meraih mainan. Rangsanglah pendengaran, perkembangan berbahasa dan kognitif dengan mencari sumber suara, mengulang -ulang beberapa kata. Rangsanglah gerak kasar dan keseimbangan dengan melatih tengkurap, berguling, telentang, posisi duduk. Rangsanglah gerak halus dan koordinasi dengan memegang menggunakan 2 tangan, meraup benda kecil, meraih benda-benda yang agak jauh, memasukan biskuit ke mulut dll.

\section{Umur 6 - 9 bulan}

Rangsanglah pendengaran, perkembangan berbahasa, emosi dan kognitif dengan memanggil namanya, memanggil mama-papa, mengulang-ulang beberapa kata. Rangsanglah gerak kasar, keseimbangan dan kemandirian dengan latihan duduk, merangkak, berdiri, melangkah berpegangan. Rangsanglah gerak halus, koordinasi visual, kognitif dan kemandirian dengan bersalaman, bertepuk tangan, melambaikan tangan, menunjuk ke benda-benda yang agak jauh.

\section{Umur 9 - 12 bulan}

Rangsanglah penglihatan, pendengaran, perkembangan berbahasa, kognitif dan komunikasi dengan menyebutkan nama-nama orang di dalam keluarga, mengulang kata-kata yang sering digunakan pada bayi. Rangsanglah perkembangan gerak halus, koordinasi, kognitif dan kemandirian dan sosial dengan memasukkan benda kedalam tempat dan mengeluarkannya lagi, minum dari gelas, menggelindingkan bola ke orang lain. Rangsanglah gerak kasar dengan berdiri, berjalan berpegangan.

\section{Umur 12 bulan - 18 bulan}

Rangsanglah gerak halus, koordinasi visual dan kognitif dengan: mencoret-coret, menyusun kubus, balok, memasukkan dan mengeluarkan benda-benda kecil dari wadahnya. Rangsanglah gerak halus, kemandirian dan kognitif dengan bermain menggunakan boneka, alat-alat rumah tangga, sendok garpu, belajar melepas celana dan baju. Rangsanglah gerak kasar, keseimbangan dan kognitif dengan berjalan tanpa berpegangan, agak cepat, berjalan mundur, memanjat kursi, tangga, menendang bola Rangsanglah perkembangan berbahasa dan kognitif dengan nama-nama benda, perintah sederhana.

\section{Umur 18 bulan - 24 bulan}

Rangsanglah perkembangan berbahasa, penglihatan, kognitif dan sosial dengan bertanya, menyebutkan nama gambar, bagian-bagian tubuh anak, binatang, benda-benda di sekitar rumah, kegiatan sehari-hari. Rangsanglah kemampuan gerak halus, kemandirian, dan kognitif dengan berlatih mencuci tangan, menyikat gigi, memakai celana, baju, menggambar garis. Rangsanglah gerak kasar, koordinasi, sosial dan kognitif dengan bermain melempar bola, melompat.

\section{Umur 2 - 3 tahun}

Rangsanglah perkembangan berbahasa dan kognitif dengan menyebutkan warna, kata sifat yang sering digunakan (besar-kecil, panas-dingin, banyak-sedikit, tinggi-rendah, enak-tidak enak), kegunaan benda 
sehari-hari, menghitung benda-benda. Rangsanglah perkembangan gerak halus, kemandirian dan sosial dengan memakai baju sendiri, menyikat gigi, bermain kartu, menyebutkan nama teman, menggambar garis dan lingkaran, menggambar manusia. Rangsanglah gerak kasar dan keseimbangan dengan berdiri satu kaki.

Bilamana terjadi keterlambatan perkembangan, maka dilakukan intervensi yang spesifik sesuai dengan jenis keterlambatannya. Setelah umur 3 tahun umumnya intervensi diarahkan untuk perkembangan kesiapan sekolah, antara lain kesiapan untuk menulis, mengenal bentuk huruf dan angka, berhitung sederhana, mengerti perintah-perintah sederhana, kemandirian dan sosial. ${ }^{6,22}$

\section{Daftar Pustaka}

1. Bennet FC, Guralnick MJ. Effectiveness of developmental intervention in the first five years of Live. Dalam: Blackman JA, penyunting. Developmental and behavior: The very young child. Pediat Clin North Am 1991; 38:1513-28.

2. Allen MC. The high risk infant. Dalam : Batshaw ML, penyunting. The child with developmental disabilities. Pediat Clin North Am 1993; 40:479 - 90.

3. Spiker D, Kathlen H. Early intervention service. Dalam: Levine MD, Carey WB, Crocker AC, penyunting. Developmental Behavioral Pediatrics; edisi ke-3. Tokyo: Saunders, 1999;793-802.

4. Stoll BJ, Kliegman RM. The high risk infant. Dalam Bergman, Kliegman, Jenson, penyunting. Nelson Text book of Pediatric. Edisi ke 16. Tokyo: Saunders, 2000;474-85

5. Nelson, CA. The Neurobiological bases of early intervention. Dalam Shonkoff JP, Meisels SJ, penyunting. Handbook of Early Childhood Intervention. Edisi ke2. Cambridge: University Press, 2000:204-30.

6. Briker D, Veltman M. Early intervention programs: child focused approaches. Dalam: Meisels SJ \& Shonkoff JP, Handbook of Early Childhood Intervention. Edisi ke1. Cambridge: University Press, 1990:373-99.

7. Chugani HT. Biological basis of emotions: brain systems and brain development. Dalam: Warhol JG, Shelov SP, penyunting. New Perspectives in Early Emotional Development. Miami: Johnson \& Johnson Pediatric Institute, 1998:5-16
8. Ramey CT, Ramey S. Early intervention: optimizing development for children with disabilities and risk conditions. Dalam: Wolraich ML, penyunting. Disorders of Development Learning; edisi ke-2. St. Louis: Mosby, 1996:141-63.

9. Rauh VA, Nurcombe B, Achenbac T, Howell C. Motherinfant transaction program. Dalam: Lester BM, Tronick EZ, penyunting. Stimulation and the preterm infant. Clin Perinatol 1990; 17:31-45

10. Lester BM, Tronick EZ. Introduction: Guidelines for stimulation with preterm infants. Dalam: Lester BM, Tronick Ezn, penyunting. Stimulation and the preterm infant. Clin Perinatol 1990; 17:xv-xviii

11. Essa A. Introduction to early childhood education. Edisi ke-2. Melbourne: Delmar Publishers, 1996:215-399

12. Gorski PA, Huntington L, Lewkowicz DJ. Handling preterm infants in hospital. Dalam: Lester BM, Tronick EZ, penyunting. Stimulation and the preterm infant. Clin Perinatol 1990;17:103-112

13. Resnick MB, Eyler FD, Nelson RM, Eitzman DV, Bucciarelli. Developmental intervention for low birth weight infant. Pediatrics 1987; $80: 68$ - 74

14. Gallagher JJ. The family as a focus for intervention. Dalam: Meisels SJ, Shonkoff JP, penyunting. Handbook of Early Childhood Intervention. Edisi pertama. Cambridge: Unversity Press, 1990:540-59

15. Powell C, Grantham G, McGregor S. Home visiting of varying frequency and child development. Pediatrics 1989 ; 84: 157-64.

16. Seitz V, Provence S. Caregiver focused models of early intervention. Dalam: Meisels SJ \& Shonkoff JP, Handbook of Early Childhood Intervention. Edisi pertama. Cambridge: University Press, 1990:400-27.

17. Brooks JB. The processs of parenting. Edisi ke-3. London: Mayfield, 1991:138-222.

18. Martin CA, Colbert KK. Parenting, a life span perspective. New York: McGraw-Hill, 1997. h. 105-38 dan 257281.

19. Rauh VA, Nurcombe B, Achenbac T, Howell C. Motherinfant transaction Program. Dalam : Lester BM, Tronick EZ, penyunting. Stimulation and the preterm infant. Clin Perinatol 1990; 17:31-45

20. Vietze, PM. Parental stimulation of high risk infants in naturalistic settings. Dalam: Lester BM, Tronick EZ, penyunting. Stimulation and the preterm infant. Clin Perinatol 1990; 17:11-30.

21. Hamner TJ, Turner Ph. Parenting in contemporary society. Edisi ke-2. New Jersey: Prentice Hall, 1990:3155 
Sari Pediatri, Vol. 8, No. 3, Desember 2006

22. Shelov SP, Hannemann RE. Caring for your baby and young children. New York : The American Academy of Pediatrics, 1998: 137-321

23. Departemen kesehatan, UNICEF,WHO. Pedoman Stimulasi Dini Perkembangan Anak. Jakarta: 1990. h. 15-54

24. Pusat pengembangan dan latihan rehabilitasi para cacat bersumberdaya masyarakat. Kegiatan khusus untuk membantu perkembangan anak. Solo: 1995.
h. 1-21

25. Departemen kesehatan. Pedoman deteksi dini tumbuh kembang balita. Edisi ke-8. Jakarta: 1994. h. 92-110.

26. Sroufe LA, Cooper RG, DeHart GB. Child Development, Its Nature and Course; edisi ke-3. New York: McGraw-Hill, 1996. h. 114-326.

27. Frankenburg WK, Dodds J, Archer P. Denver II Training Manual. Denver: Denver Developmental Materials, 1990. h. 43-46 